\title{
Selective Nasogastric Decompression after Elective Laparotomy
}

\author{
Abdul Ghani Soomro, Faisal Ghani Siddiqui, Ahmed H ussain Agha, \\ Abdul Sattar Memon and Noshad Ahmed Shaikh
}

\begin{abstract}
OBJECTIVE: This study was conducted to evaluate the need or other wise for use of nasogastric decompression after elective laparotomy, as many studies suggest that routine nasogastric decompression is unnecessary after elective laparotomy and may in fact be associated with an increased incidence of complications. Despite these reports the nasogastric tube is routinely used for decompression, believing that its use significantly decreases the risk of post-operative nausea, vomiting, aspiration pneumonia, wound dehiscence and anastomotic leakage.

DESIGN: Descriptive case-series.

PLACE AND DURATION OF STUDY: Surgical Unit-II, Liaquat University Hospital Jamshoro from July 2005 to July 2007.

PATIENTS AND METHODS: Seventy patients were included in this study. A proforma was designed and all the findings were recorded. All the patients were observed regarding the development of complications like, post-operative nausea, vomiting, pulmonary complications, abdominal distention and return of bowel sounds.

RESULTS: Out of 70 studied cases 45 (64.2\%) were males and 25 (35.7\%) were females. Age ranged from 10 years to 70 years and mean age was 33 years. Postoperative pulmonary complications like atelectasis and pneumonia were seen in $3(4.2 \%)$ out of 70 patients. The commonest operation performed was reversal of ileostomy and resection with end-to-end anastomosis. Postoperative nausea and vomiting were seen in 10 (14.2\%) cases.

CONCLUSION: The study did not support the routine use of nasogastric decompression.
\end{abstract}

KEY WORDS: Selective, Laparotomy, Nasogastric Tube, Complications.

\section{INTRODUCTION}

For the past three hundred years, nasogastric tube has been inserted into the stomach for the purpose of evacuating gas and liquid. The reason for such an activity may be therapeutic, as in patients with distention and vomiting from bowel obstruction, diagnostic as in case of gastrointestinal bleeding; or prophylactic, as in patients having major abdominal surgery. Prophylactic use of nasogastric tube after abdominal operations is going on for the last one century as the standard of care, traditionally used by most surgeons, common practice which is unquestioned and routine $e^{1-7}$ The objective of this study is to evaluate the efficacy of prophylactic use of gastric decompression, reducing the postoperative complications such as pneumonia, atelactasis, wound infection, wound dehiscence incisional hernia; and early discharge from hospital.

\section{PATIENTS AND METHODS}

This descriptive case study was carried out at Liaquat University Hospital Jamshoro from July 2005 to July 2007. Seventy patients were included in the study. Patients were monitored regarding merits and demer- its of using nasogastric tube after abdominal surgery. All types of operations were included in this study ranging from operations for abdominal trauma, reversal ileostomy, closure of colostomy, hemicolectomy, resection with end-to-end anastomosis and bypass procedure for advanced gastric outlet obstruction. Laparoscopic procedure was not included in the study. The outcome measures sought included, appearance of the bowel sounds, passage of flatus, pulmonary complications, wound infection, length of hospital stay, wound dehiscence anastomotic leakage, nausea and/or vomiting, need for tube insertion/ reinsertion or tube related discomfort.

\section{RESULTS}

Seventy patients were included in the study. Forty-five $(64.2 \%)$ patients were males and twenty-five (35.7\%) were females. Age ranged from 10 years to 70 years. Thirty-seven (52.8\%) patients were in the age group of 21-40 years. The mean age was 33 years. The commonest operations performed were reversal of ileostomy and resection with end-to-end anastomosis (Table I). Pulmonary complications were seen in 3 $(4.2 \%)$ cases, wound infection in $6(8.57 \%)$ cases, 
wound dehiscence in $2(2.8 \%)$ cases and anastomotic leakage in $3(4.2 \%)$ cases. Two $(2.8 \%)$ patients developed faecal fistula. Both were operated for closure of sigmoid colostomy and both of them improved on conservative treatment. Two patients expired in the series due to septicemia, myocardial infarction and pulmonary edema, both were above 50 years of age (Table II).

\section{TABLE I: OPERATIVE PROCEDURES}

\begin{tabular}{|l|c|c|}
\hline \multicolumn{1}{|c|}{ Name } & $\begin{array}{c}\text { No. of } \\
\text { Patients }\end{array}$ & $\begin{array}{c}\text { Per- } \\
\text { centage }\end{array}$ \\
\hline Ileostomy Reversal (Typhoid) & 30 & 42.85 \\
\hline $\begin{array}{l}\text { Ileostomy Reversal } \\
\text { (Tuberculosis) }\end{array}$ & 06 & 8.57 \\
\hline $\begin{array}{l}\text { Hemicolectomy (Tuberculosis } \\
\text { and Carcinoma caecum) }\end{array}$ & 15 & 21 \\
\hline $\begin{array}{l}\text { Transverse Colostomy Closure } \\
\text { (Fire arm injury) }\end{array}$ & 04 & 5.7 \\
\hline Adhesive obstruction & 03 & 4.28 \\
\hline Abdominal trauma & 04 & 5.75 \\
\hline $\begin{array}{l}\text { Sigmoid colostomy Reversal } \\
\text { (fire arm injury, sigmoid volvu- } \\
\text { lus and recto vaginal fistula) }\end{array}$ & 04 & 5.75 \\
\hline $\begin{array}{l}\text { Gastrojejunostomy for ad- } \\
\text { vanced gastric outlet carcinoma }\end{array}$ & 04 & 5.75 \\
\hline Total & $\mathbf{7 0}$ & $\mathbf{9 9 . 7}$ \\
\hline
\end{tabular}

TABLE II: COMPLICATIONS

\begin{tabular}{|l|c|c|}
\hline \multicolumn{1}{|c|}{ Type Of Complication } & Number & \% \\
\hline Wound infection & 6 & 8.57 \\
\hline $\begin{array}{l}\text { Pulmonary Complications } \\
\text { (Pneumonia, Atelectasis) }\end{array}$ & 3 & 4.2 \\
\hline $\begin{array}{l}\text { Nausea/Vomiting and } \\
\text { abdominal distension }\end{array}$ & 10 & 14.2 \\
\hline Wound Dehiscence & 2 & 2.85 \\
\hline Anastomotic leakage & 3 & 4.2 \\
\hline Burst Abdomen & 1 & 1.42 \\
\hline $\begin{array}{l}\text { Bleeding from nose } \\
\text { (tube related) }\end{array}$ & 1 & 1.42 \\
\hline Deep vein thrombosis & 1 & 1.42 \\
\hline Death & 2 & 2.85 \\
\hline Total & $\mathbf{2 9}$ & $\mathbf{4 1 . 1 3}$ \\
\hline
\end{tabular}

\section{DISCUSSION}

Routine nasogastric decompression is widely practised after laparotomy. The practice is based largely on tradition and the perception that nasogastric decompression protects patients from postoperative complications like nausea, vomiting, aspiration pneumonia, wound complications and anastomotic leakage; and may allow for earlier hospital discharge. Nasogastric decompression has changed dramatically through improvements in the tube design and its intended use more than six decades ago ${ }^{7,8}$. Many of the studies advocating nasogastric decompression, recommend oral intake with gastric tube in place, a practice that would not be advocated by most surgeons today. Thus the foundation on which nasogastric decompression is based has changed over the past several decades, necessitating a re-evaluation of its use ${ }^{9}$. Majority of patients complain about the irritation in the throat because of the tube, a common complain reported by many ${ }^{10-13}$. The discomfort caused by routine nasogastric decompression is therefore one of the major reasons that surgeons have considered selective use of nasogastric decompression ${ }^{9,14}$. Though it appears that the incidence of abdominal distention and vomiting is increased in the absence of nasogastric decompression but patients may develop these complications even with nasogastric tube in place $^{9}$. In this series, only $4(5.71 \%)$ patients out of 70 required insertion of the nasogastric tube postoperatively for 24-48 hours because of abdominal distension, nausea and/or vomiting. Had nasogastric tube been used as routine in all patients than $64(91.42 \%)$ patients would have suffered from undue discomfort caused by the tube where it was not needed. Regarding post operative complications wound infection was seen in 6 (8.5\%) patients. Pulmonary complication like pneumonia and atelactesis was seen in $3(4.2 \%)$. Furthermore based on this study nasogastric decompression does not prevent wound infection or dehiscence nor, does it decrease total hospital length or the number of days to first oral intake which is also described in literature ${ }^{9}$.

\section{CONCLUSION}

Routine nasogastric decompression should not be done in patients undergoing elective laparotomy as not much of abdominal distension, nausea/vomiting were seen postoperatively. Only $4(5.7 \%)$ patients required insertion of tube postoperatively. On the other hand with routine use of nasogastric tube there are more chances of pulmonary complications and also a persistence sense of irritation and foreign body in the throat. It is concluded that routine nasogastric decompression does not accomplish any of its in- 
tended goals and so should be abdondoned in favour of selective use of nasgastric tube in patients undergoing elective laparotomy.

\section{REFERENCES}

1. Isbister $\mathrm{WH}$. Is postoperative gastric decompression really necessary? Am J Surg 1970; 120:511.

2. De Costa H, Taylor EW. Patient management following uncomplicated elective gastrointestinal operations. Br J Clin Pract 1990; 44: 552-5.

3. Herrington JL. Avoidance of the routine use of postoperative gastric suction. Surg Gynecol Obstet 1965; 121:351-2.

4. Gerber A. An appraisal of paralytic ileus and the necessity for post-operative gastrointestinal suction. Surg Gynecol Obstet 1963; 117:294-6.

5. Jamieson WG, DeRose G, Harris KA. Routine nasogastric decompression after abdominal surgery? Can J Surg 1992; 35:577-8.

6. Sagar PM, Kruegener G, MacFie J. Nasogastric intubation and elective abdominal surgery. $\mathrm{Br} \mathrm{J}$ Surg 1992; 79: 1127-31.

7. Wangensteen $\mathrm{OH}$, Paine JR. Treatment of acute intestinal obstruction by suction with the duodenal tube. JAMA 1933; 101:1532-9.
8. Paine JR, Carlson HA, Wangensteen $\mathrm{OH}$. The Postoperative control of distension, nausea and vomiting. JAMA 1933; 100:1910-7.

9. Cheatham ML, Chapman WC. A Meta-analysis of selective versus routine nasogastric decompression after elective laparotomy. An Surg 1995; 221 (5): 469-78.

10. Bauer JJ, Gelernt IM, Salky BA, Kreel L. Is routine postoperative nasogastric decompression really necessary? Ann Surg 1985; 201:233-6.

11. Cheadle WG, Vitale GC, Mackie CR, Chuschieri A. Prophylactic postoperative nasogastric decompression: a prospective study of its requirement and the influence of eimetidine in 200 patients. Ann Surg 1985; 202:361-6.

12. Bashey AA. Cuschieri A. Patient comfort after upper abdominal surgery: effect of routine nasogastric suction. J R Coll Surg Edinb 1985; 30:97-100.

13. Nathan BN, Pain JA. Nasogastric suction after elective abdominal surgery: a randomized study. Ann R Coll Surg 1991;73:291-4.

14. Nelson R, Tse B, Edwards S. Systematic review of prophylactic nasogastric dcompression after abdominal operations. Br J Surg 2005;92:673-80.

AUTHOR AFFILIATION:
Dr. Abdul Ghani Soomro (Corresponding Author)
Senior Registrar, Department of Surgery
Liaquat University of Medical \& Health Sciences,
(LUMHS) Jamshoro, Sindh-Pakistan.
Dr. FaisalGhani Siddiqui
Assistant Professor, Department of Surgery
LUMHS Jamshoro, Sindh-Pakistan.
Dr. Ahmed Hussain Agha
Postgraduate Student, Department of Surgery
LUMHS Jamshoro, Sindh-Pakistan
Dr. Abdul Sattar Memon
Professor, Department of Surgery
LUMHS Jamshoro, Sindh-Pakistan.
Prof. Noshad Ahmed Shaikh
Professor of Surgery and Vice Chancellor
LUMHS Jamshoro, Sindh - Pakistan.

